\title{
Divided we fall: the commodification of primary medical care
}

\author{
Allowing segmentation of general practice is a risky strategy with largely unknown consequences
}

\author{
Bruce Guthrie professor of primary care medicine ${ }^{1}$, Stewart W Mercer professor of primary care \\ research ${ }^{2}$
}

${ }^{1}$ Population Health Sciences Division, University of Dundee, Dundee, UK; ${ }^{2}$ Institute of Health and Wellbeing, University of Glasgow, Glasgow, UK

\begin{abstract}
Healthcare is intrinsically complex, and all healthcare systems have struggled to find an appropriate balance between generalism and specialism. ${ }^{1}$ Managing coordination and transitions across boundaries between specialist services is also a growing challenge in a world of multimorbidity. ${ }^{1}$ General practice is the core element of generalist provision since hospital doctors have become increasingly specialist, but recent developments risk fragmenting generalist primary medical care. The Nuffield Trust recently published a report examining the implications of the trend towards "segmenting" populations to provide different types of care for people with different needs. ${ }^{2}$ Concerns about this are neither new nor unique to the UK. Julian Tudor Hart's expression of the inverse care law in the 1970s (that the quality of medical care is usually worse for those with higher need) was underpinned by concerns that commodification of care would undermine universality and holistic generalist care. ${ }^{3}$ Similarly, in the US there has been considerable recent debate about the "Amazon-ization" of primary care, with concerns that echo those in the Nuffield report. ${ }^{4}$
\end{abstract}

Population segmentation is also nothing new. Geriatricians, paediatricians, and disease specialists provide care to segments of the population. In UK general practice, it has become routine to recall patients for structured care in clinics focused on single chronic conditions such as diabetes and asthma. What is new is the use of large electronic data sources to segment primary care populations, and the creation of specific services to serve particular segments. Initial activity focused on using routine data to try to identify the small numbers of people at the highest risk of hospital admission, ${ }^{5}$ but the next turn of the screw is to apply this logic to the whole population.

\section{Cherry picking}

The Nuffield report expresses particular concern about damage to generalist primary care from services providing rapid access to transactional care for episodic needs, also pointing out that these new services cost much more than core primary care. ${ }^{6}$ As an example, the new GP at Hand service in London offers anytime video appointments with a promise that most people will be "seen" within two hours. ${ }^{7}$ Registration with the underlying NHS practice is as an "out of area" patient, with face-to-face appointments offered at five widely dispersed sites, and home visits guaranteed only for those in the practice area.

The service is likely to be popular with younger, fitter patients seeking rapid, access for episodic problems and minor illnesses. However, people developing more complex needs, such as those with mental health problems and multimorbidity, are likely to be referred back to local practices. ${ }^{8}$ If this happens, then the new service will be paid the same capitation fee to care for people when healthy that the local practice receives to care for them when they become sick. Segmentation of primary care across different services therefore creates the space for cherry picking, which in the end will disadvantage sicker and more challenging patients, not least if large numbers of professionals also opt for the easier life of providing episodic care. Put another way, we run the risk of prioritising access for the healthier over comprehensive generalist care for the sicker. Is this really the NHS we want?

\section{Evidence first}

We don't yet know if steering segments of the population to separate access focused services will improve care ${ }^{69}$ The National Institute for Health and Care Excellence multimorbidity guideline found no evidence that routine data could effectively identify individuals needing tailored care ${ }^{10}$ and population segments are also dynamic, as individuals move in and out of different health states. ${ }^{11}$ People at high risk of hospital admission revert to average risk within two years, ${ }^{5}$ and the healthy young person with episodic health needs now can easily develop serious mental or physical health needs that require continuity of care.

Creating new service silos for patients and professionals to negotiate is therefore risky, and investment in new services is anyway not the solution if lack of resources in existing services 
is the problem. Investment in generalist primary care is required instead because "if general practice fails, the whole NHS fails." 12 Two recommendations of the Nuffield report stand out. ${ }^{2}$ Firstly, the report recommends that generalist multidisciplinary "micro-teams" are created to deliver comprehensive primary care. Micro-teams of two to three wholetime equivalent GPs embedded in a wider team seem a reasonable starting point for teams that are large enough to be sustainable and small enough to be personal and effective. However, clinical micro-teams will need larger organisational support to develop and sustain themselves, because functions such as data analysis and facilitation of change are best provided at a much larger scale.

Secondly, radical change needs careful and long term system-wide evaluation, whether it is new models of integrated primary care or a brave new world of primary care segmented services. ${ }^{13}$ Evaluation could usefully take advantage of the natural experiments created by devolution of responsibility for healthcare in the UK, where the constituent countries face similar challenges but have chosen to respond to them in different ways. ${ }^{14}$

Competing interests: We have read and understood BMJ policy on declaration of interests and have no relevant interests to declare.

Provenance and peer review: Commissioned; not externally peer reviewed.
1 Barnett K, Mercer SW, Norbury M, Watt G, Wyke S, Guthrie B. Epidemiology of multimorbidity and implications for health care, research, and medical education: a cross-sectional study. Lancet 2012;380:37-43. 10.1016/S0140-6736(12)60240-2 22579043

2 Rosen R. Divided we fall: getting the best out of general practice. Nuffield Trust, 2018. https://www.nuffieldtrust.org.uk/research/divided-we-fall-getting-the-best-out-of-generalpractice

3 Hart JT. The inverse care law. Lancet 1971;1:405-12. 10.1016/S0140-6736(71)92410-X 4100731

4 Has primary care been Amazon-ised? 2018. https://medstro.com/groups/nejm-groupopen-forum/discussions/556.

5 Roland M, Dusheiko M, Gravelle H, Parker S. Follow up of people aged 65 and over with a history of emergency admissions: analysis of routine admission data. BMJ 2005;330:289-92. 10.1136/bmj.330.7486.289 15695276

6 National Audit Office. Improving patient access to general practice London. National Audit Office, 2017.

7 GP at Hand. Our service. https://www.gpathand.nhs.uk/our-nhs-service.

$8 \mathrm{GP}$ at Hand. What if I have a complex medical history? https://support.gpathand.nhs.uk/ hc/en-us/articles/115005432445-What-if--have-a-complex-medical-history-

9 Chen CE, Chen CT, Hu J, Mehrotra A. Walk-in clinics versus physician offices and emergency rooms for urgent care and chronic disease management. Cochrane Database Syst Rev 2017;2:CD011774.28211045

10 National Institute for Health and Care Excellence. NG56 Multimorbidity: clinical assessment and management. NICE, 2016.

11 Rosen R. Are disruptive innovators in GP provision strengthening or weakening the NHS?BMJ 2017;359:j5470. 10.1136/bmj.j5470 29187352

12 Roland M, Everington S. Tackling the crisis in general practice. BMJ 2016;352:i942. 10.1136/bmj.i942 26887896

13 Guthrie B, Gillies J, Calderwood C, Smith G, Mercer S. Developing middle-ground research to support primary care transformation. Br J Gen Pract 2017;67:498-9. 10.3399/bjgp17X693209 29074679

14 Smith Gl, Mercer SW, Gillies JC, McDevitt A. Improving together: a new quality framework for GP clusters in Scotland. Br J Gen Pract 2017;67:294-5.

10.3399/bjgp17X691601 28663413

Published by the BMJ Publishing Group Limited. For permission to use (where not already granted under a licence) please go to http://group.bmj.com/group/rights-licensing/ permissions 